\title{
Stereopsis deficiency treatment using virtual reality games in exotropic candidate for firefighter
}

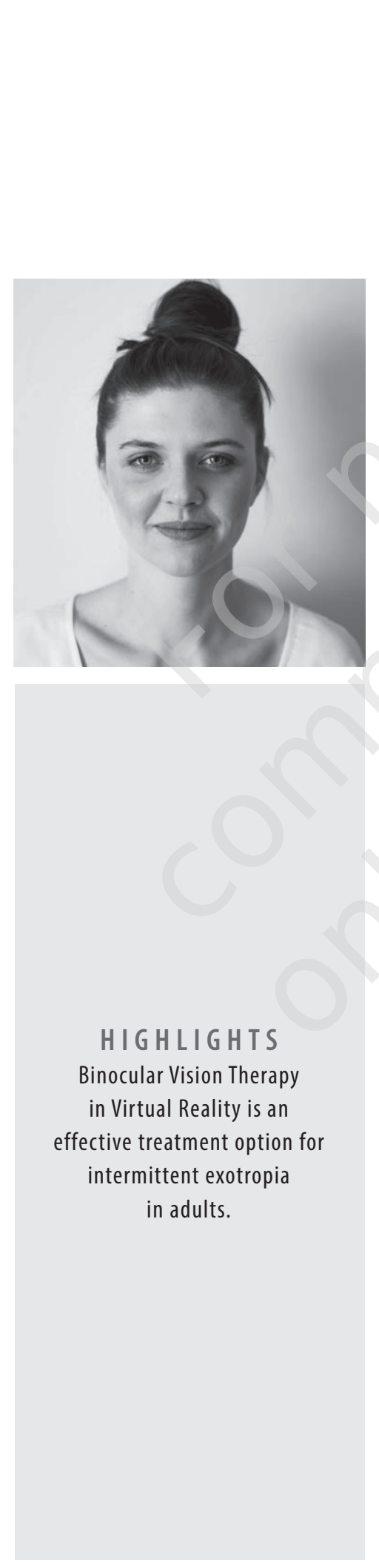

\author{
Dorota Maciaszek ${ }^{1,4}$, Monika Wojtczak-Kwaśniewska ${ }^{2,3,4}$ \\ 'Department of Ophthalmology, Chair of Ophthalmology and Optometry, Poznan University of Medical Sciences, Poland \\ Head of Department: prof. Marcin Stopa, MD, PhD \\ ${ }^{2}$ Laboratory of Vision Science and Optometry, Faculty of Physics, Adam Mickiewicz University, Poznan, Poland \\ Dean of Faculty: prof. Roman Gołębiewski, PhD \\ ${ }^{3}$ Laboratory of Vision and Neuroscience, Nanobiomedical Centre, Adam Mickiewicz University, Poznan, Poland \\ Director: prof. Stefan Jurga \\ ${ }^{4}$ Optometry and Vision Therapy Center, Poznan, Poland \\ Head: prof. Anna Przekoracka-Krawczyk, MD, PhD
}

\section{ABSTRACT}

Background: Impaired stereopsis very often limits career options for patients with binocular vision disorders. Eyesight requirements for some occupations like police officers and firefighters usually include perfect visual acuity. In Poland, candidates for these professions must also demonstrate perfect stereopsis. The presented case study aims to demonstrate that vision therapy $\left(\mathrm{VT}^{1}\right)$ mixed with new technologies may be an effective treatment for young adults who do not meet the chosen occupation's visual requirements.

Case report: A case of a young man diagnosed with intermittent exotropia and poor stereopsis is discussed. Poor stereopsis did not allow him to pass the ophthalmological qualification tests to the fire academy. Vision therapy was implemented to improve stereopsis. The case report presents the patient's treatment implemented within 4 years. The patient started with prismatic correction, then received the office-based VT with home reinforcement. The improvement in fusional vergence and the control of deviation was observed. Nevertheless, the patient was still stereo-deficient. 3 years later, Binocular Vision Therapy in Virtual Reality $\left(\mathrm{BVTVR}^{2}\right)$ was recommended. The patient received home-based therapy for 16 weeks (60 minutes per day), which has resulted in significant improvement of stereopsis. As a result, he finally met the visual requirements to become a firefighter.

Conclusion: BVTVR appears to be a promising rehabilitation method for patients with poor stereopsis. Three-dimensional anti-suppression therapy and dynamic, real-life stereopsis training seem to be a more effective treatment of poor stereopsis compared to standard VT techniques.

Key words: intermittent exotropia, stereopsis, strabismus, virtual reality, vision therapy

${ }^{1}$ Vision therapy.

${ }^{2}$ Binocular vision therapy in virtual reality. 


\section{INTRODUCTION}

Impaired stereopsis is a common deficit associated with different binocular vision anomalies such as amblyopia, strabismus or a combination of the two. However, stereopsis is more impacted in strabismic than in anisometropic amblyopia [1]. Moreover, individuals with constant strabismus are generally stereo-blind. These observations strongly suggest that the ocular alignment is crucial for normal stereoscopic vision.

One of the common binocular vision disorders is intermittent exotropia $\left(\mathrm{IXT}^{3}\right)$, where one eye intermittently deviates outwards. Affected patients are not often aware when their eyes are misaligned and they do not experience double vision, due to the anti-diplopic mechanism - suppression of the deviated eye. According to the size of the near and distance deviation, the strabismus manifests at different frequencies. Theoretically, the greater the deviation, the worse the control of eye alignment. Nevertheless, cases were observed where, with a relatively small deviation (up to $10 \mathrm{PD}$ ), patients had very poor eye alignment control and significantly impaired stereopsis [2]. Interestingly, eye realignment may lead to the recovery of stereopsis [3].

The treatment of intermittent exotropia includes: overminus lens, prisms, occlusion, extraocular muscle surgery, and vision therapy (VT). The last two seem to have the highest efficacy. The success rate of VT and surgery is 59\% and $46 \%$, respectively. However, the success rate of the surgery differed depending on whether functional and cosmetic aspect was considered (43\% vs. 61\%) [4]. Moreover, it is worth noting that there is still a tendency for the IXT to recur after the surgery [5].

The treatment sequence of VT usually includes accommodative, oculomotor, near and distance vergence techniques. Anti-suppression techniques are also incorporated to maintain the simultaneous perception of the right and left eye [6-8].

At present, virtual reality (VR) seems to create perfect condition for anti-suppression training, since in head-mounted display goggles (HMD goggles), it is possible to project images independently in front of the right and left eye during binocular viewing conditions (dichoptic stimulation). Dynamic training at variable distances allows for a rehabilitation in real-life conditions.

As a telemedical tool, the therapeutic VR system allows providers to monitor and change game settings remotely which positively influences the patient's motivation and compliance while giving the patient the opportunity to undergo training sessions at home. Therefore, VR addresses the problem of excessive time spent on regular office visits and patient adherence to daily home therapy. Both of these issues were reported as main disadvantages of VT [4]. This case study addresses the effectiveness of vision therapy and the crucial role of Binocular Vision Therapy in Virtual Reality (BVTVR) in a young patient diagnosed with IXT.

\section{CASE REPORT}

A 21-year-old man presented to the Optometry and Vision Therapy Center in Poznan, Poland. The patient was motivated to begin vision therapy because of his occupational plans. He did not pass the stereopsis test in the recruitment process for the fire academy.

\section{Initial examination}

The patient has had a prismatic correction for 2 years. The prescription was 2-PD BI in the right eye (OD) and 3-PD BI in the left eye (OS). Uncorrected visual acuity at a distance was 20/20 in each eye. Patient was hyperopic (OD +0,75 D, OS $+0,75 \mathrm{D})$. Cover test (CT) at distance and near found 10-PD intermittent exotropia OS. The patient had poor eye alignment control. The frequency of the exotropia was $90 \%$ at all distances. Worth 4-dot test at distance and near revealed intermittent suppression of OS. Vergence ranges at distance and near with a prism bar and near point of convergence (NPC) could not be assessed because of suppression. Random-dot stereogram testing (Lang I and II) and contour stereopsis (Wirt circles) were not present. Clinical findings are outlined in table 1.

A treatment program of 12 weekly office-based optometric vision therapy sessions was recommended to decrease suppression, stabilize fusion and stimulate stereopsis.

\section{Follow-up visit after VT}

The follow-up visit indicated a significant improvement in binocular vision. The patient had moderate control of eye alignment. CT showed 10-PD intermittent OS exotropia and eye misalignment only $10 \%$ of the time. Worth 4-dot testing found flat fusion at all distances, full convergence range and excessive fusion ranges. Still, he was not able to pass random-dot stereogram testing and contour stereopsis was reduced. He continued vision therapy (12 sessions, office-based) which ended before the ophthalmological examination at the beginning of the fire school's recruitment process. A follow-up visit after the $12 \mathrm{VT}$ sessions did not take place. Before the planned visit, the patient had an ophthalmological examination and did not pass the stereopsis vision test. Due to his emotional state, he refused to participate in the control examination. He chose to participate in home-based VT and start the office-based VT again before the next recruitment process. Findings are outlined in table 1. 


\begin{tabular}{|c|c|c|c|c|c|}
\hline \multicolumn{6}{|c|}{ Summary of results. } \\
\hline & Initial examination & $\begin{array}{c}\text { Follow-up visit after } \\
\text { first VT }\end{array}$ & $\begin{array}{l}\text { Follow-up } \\
\text { visit after } \\
\text { second VT }\end{array}$ & Second examination & $\begin{array}{c}\text { Follow-up visit after } \\
\text { BVTVR }\end{array}$ \\
\hline Cover test & $\begin{array}{l}\text { distance/near: } \\
\text { 10-PD intermittent } \\
\text { exotropia OS } \\
90 \% \text { frequency of the } \\
\text { deviation }\end{array}$ & $\begin{array}{l}\text { distance/near: } \\
\text { 10-PD intermittent } \\
\text { exotropia OS } \\
10 \% \text { frequency of the } \\
\text { deviation }\end{array}$ & \multirow{5}{*}{$\begin{array}{l}\text { Lack of data. } \\
\text { The patient did } \\
\text { not show up. }\end{array}$} & $\begin{array}{l}\text { distance/near: } \\
\text { 7-PD exophoria }\end{array}$ & $\begin{array}{l}\text { distance/near: } \\
\text { 7-PD exophoria }\end{array}$ \\
\hline Worth 4-dot test & $\begin{array}{l}\text { intermittent suppression } \\
\text { of OS at all distances }\end{array}$ & flat fusion at all distances & & flat fusion at all distances & flat fusion at all distances \\
\hline NPC & $32 / 25 \mathrm{~cm}$ or tropia & to the nose & & to the nose & Tto the nose \\
\hline Vergence ranges & suppression & $\begin{array}{l}\text { DBI: } 12 / 10 \\
\text { DBO: } 16 / 12 \\
\text { NBI: } 12 / 10 \\
\text { NBO: } 25 / 20\end{array}$ & & $\begin{array}{l}\text { DBI: } 16 / 12 \\
\text { DBO: } 10 / 8 \\
\text { NBI: } 12 / 10 \\
\text { NBO: } 25 / 10\end{array}$ & $\begin{array}{l}\text { DBI: } 14 / 12 \\
\text { DBO: } 25 / 20 \\
\text { NBI: } 12 / 10 \\
\text { NBO: } 35 / 25\end{array}$ \\
\hline Stereopsis & $\begin{array}{l}\text { random-dot stereogram } \\
\text { testing - Lang Test (-) } \\
\text { contour stereopsis - Wirt } \\
\text { circles (-) }\end{array}$ & $\begin{array}{l}\text { random-dot stereogram } \\
\text { testing - Lang test (-) } \\
\text { contour stereopsis - Wirt } \\
\text { circles }\left(200^{\prime \prime}\right)\end{array}$ & & $\begin{array}{l}\text { random-dot stereogram } \\
\text { testing - Lang test (-) } \\
\text { contour stereopsis - Wirt } \\
\text { circles }\left(400^{\prime \prime}\right)\end{array}$ & $\begin{array}{l}\text { random-dot stereogram } \\
\text { testing - Lang test }\left(400^{\prime \prime}\right) \\
\text { contour stereopsis - Wirt } \\
\text { circles }\left(60^{\prime \prime}\right)\end{array}$ \\
\hline
\end{tabular}

OS - left eye; PD - prism diopter; DBI - distance base in; DBO - distance base out; NBI - near base in; NBO - near base out.

\section{Second examination}

After 3 years, the patient returned at the age of 25 , the maximum age for firefighter candidates in Poland. CT showed an exophoria of 7-PD and normal fusional ranges at distance and near. The Worth 4-dots test confirmed a stable flat fusion in near and distance. Stereopsis was still reduced. Findings are outlined in table 1.

Intensive anti-suppression and stimulating stereopsis training with the VR system (RemmedVR Sp. z o.o., Poland) was planned. The patient received home-based VT remotely administrated by the Optometrist, BVTVR 30 minutes, two times per day for 16 weeks. Games and their settings are presented in figure 1 .

\section{Follow-up visit after BVTVR}

After 4 months of remotely monitored, home-based BVTVR, the patient stated that he is experiencing a significant improvement and does not have to consciously control his eyes' alignment. He also noted a significant improvement in his perception of depth. Clinically, the patient was exophoric at distance and near by CT. Prism bar ranges increased at distance and near. The results of the stereopsis test were impressive. The patient was able to pass the random-dot stereopsis test for the first time. Contour stereopsis test results improved. Based on previous observation indicating the difficulty of answering the stereo test at the highest values, the ease of answering after BVTVR training was remarked.
The patient passed the stereopsis test and met the previously failed requirements to become a firefighter. Clinical findings are outlined in table 1.

\section{DISCUSSION}

The primary goal of treatment for IXT is to preserve the binocular vision and improve (or preserve) stereopsis. The previous studies showed that office-based VT is an effective method in treating IXT $[8,9]$. In the presented case, intermittent exotropia has been initially treated with traditional office-based VT which has resulted in improvement in fusional vergence and control of deviation, however stereopsis did not change. Implementation of new technology based on the traditional VT treatment was successful at stereopsis improving.

Studies which previously used a VR platform revealed that this approach is successful in stereopsis improving in young and adult patients with different binocular vision disorders. The first study which used a VR platform treated patients with exotropia [10]. They revealed improvement of stereopsis (and also eye alignment) of all 25 IXT patients after 6 months of training. The stereopsis improvement was also observed in adult patients with amblyopia and/or strabismus $[11,12]$. Therefore, based on these studies we could have presumed that implementation of VR would be successful in the presented case. 


\section{FIGURE 1}

Gameplay screenshots. A-D. Dichoptic viewing conditions and anti-suppression training. E. Vergence ranges training, arrows show movements of objects in convergence training. F. Stereopsis training, objects are presented with decreasing disparity stimulating depth.
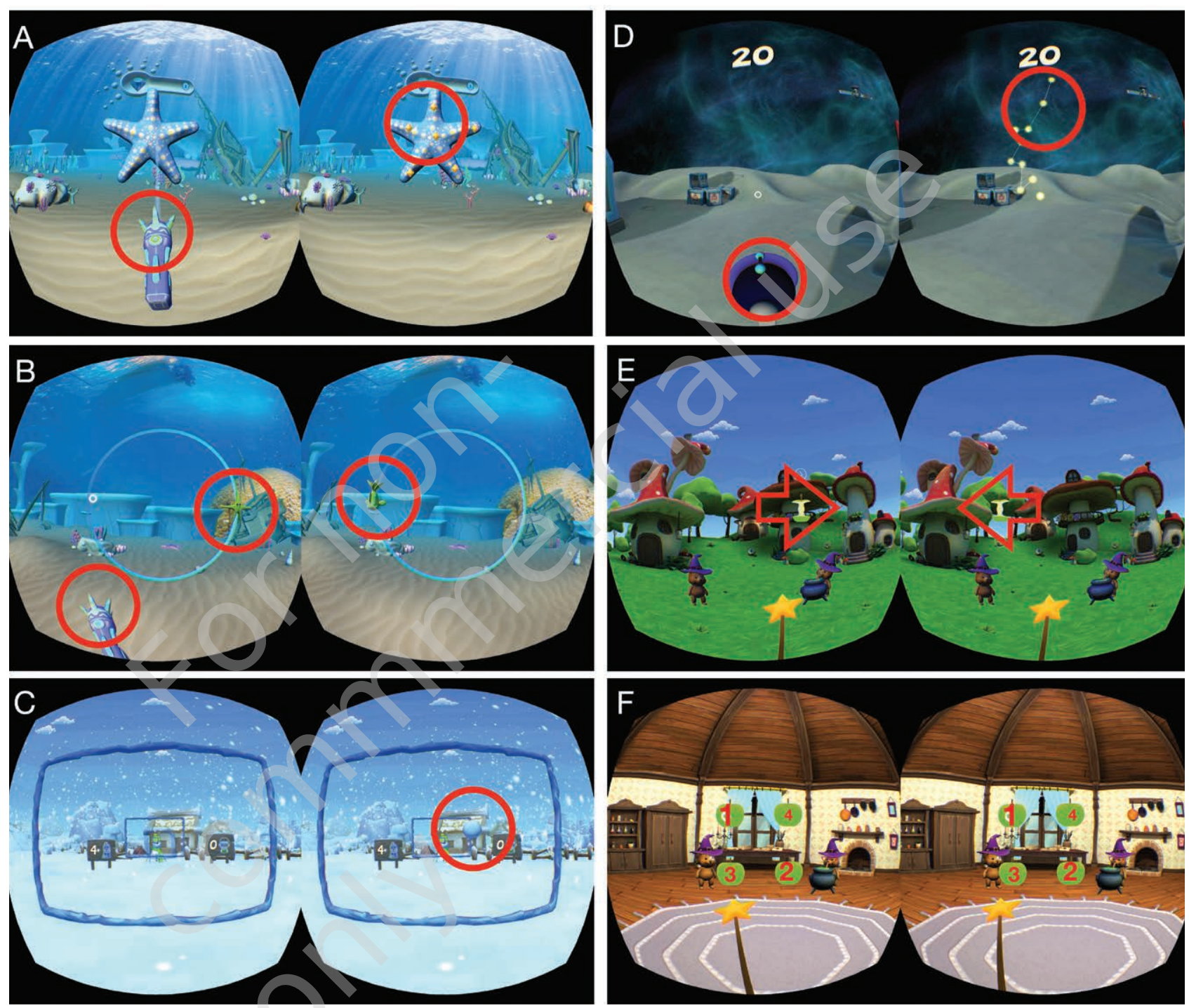

However, there is a question as to why there was no improvement of stereopsis after 6 months of conventional VT. Previous study revealed that conventional VT was effective for improving stereopsis in children [9]. We hypothesize that it could be related to the mechanisms which prevent diplopia since the study by Serrano-Pedraza et al. (2011) on patients with IXT showed that they occur even when the eyes were correctly aligned [13]. Hence, it is possible that BVTVR weakens anti-diplopic mechanisms and as a consequence significantly improve stereopsis - due to the dichoptic stimulation which may be more effective than conventional techniques in adults.
It should be noted that the presented management had a limitation of no distance stereopsis assessment. We surmise that training at dynamically changing distances in VR may have had a positive effect on the improvement of distance stereopsis. Based on the therapy progress available in the RemmedVR system, we observed that in the Magic Hut game (RemmedVR stereopsis dedicated game), the gaming score indicated significant improvement at each distance. In the range of 1-6 m, from 1200" at the beginning of therapy to $80 "$ at the end of treatment. 


\section{CONCLUSION}

Conventional VT techniques effectively improved the fusional vergence and the control of deviation but not stereopsis which is a crucial eyesight requirement for firefighter candidates. Dedicated three-dimensional, anti-suppres- sion, and dynamic, real-life stereopsis therapy in VR became a key element of a young firefighter candidate's treatment.

Figures: from the author's own materials.

\author{
CORRESPONDENCE \\ Dorota Maciaszek, MSc \\ Department of Ophthalmology, Chair of Ophthalmology \\ and Optometry, Poznan University of Medical Sciences \\ 60-806 Poznan, Rokietnicka 5D \\ phone: +48 796417370 \\ e-mail: maciaszek.d@gmail.com
}

\section{Monika Wojtczak-Kwaśniewska, MSc \\ Laboratory of Vision Science and Optometry, \\ Faculty of Physics, Adam Mickiewicz University \\ 61-614 Poznan, Uniwersytetu Poznańskiego 2 \\ phone: +48 509220481 \\ e-mail: monika.wojtczak@amu.edu.pl}

\section{ORCID}

Dorota Maciaszek - ID - http://orcid.org/0000-0002-1003-8390

Monika Wojtczak-Kwaśniewska - ID - http://orcid.org/0000-0001$-5052-1347$

\section{References}

1. Levi DM, Knill DC, Bavelier D. Stereopsis and amblyopia: A mini-review. Vision Res. 2015; 114: 17-30. https://doi.org/10.1016/j. visres.2015.01.002.

2. Stathacopoulos RA, Rosenbaum AL, Zanoni D et al. Distance stereoacuity. Assessing control in intermittent exotropia. Ophthalmology. 1993; 100(4): 495-500. https://doi.org/10.1016/S0161-6420(93)31616-7.

3. O'Connor, Tidbury LP. Stereopsis: are we assessing it in enough depth? Clin Exp Optom. 2018; 101(4): 485-94. https://doi.org/10.1111/ cxo.12655.

4. Coffey B, Wick B, Cotter S et al. Treatment options in intermittent exotropia: a critical appraisal. Optom Vis Sci. 1992; 69(5): 386-404. https://doi.org/10.1097/00006324-199205000-00008.

5. Koklanis K, Georgievski Z. Recurrence of intermittent exotropia: factors associated with surgical outcomes. Strabismus. 2009; 17(1): 37-40. https://doi.org/10.1080/09273970802678750.

6. Scheimann M, Wick B. Clinical Management of Binocular Vision: Heterophoric, Accommodative, and Eye Movement Disorders. $5^{\text {th }}$ ed. Lippincott Williams \& Wilkins 2019.

7. Peddle A, Han E, Steiner A. Vision therapy for basic exotropia in adults: 2 case studies. Optometry. 2011; 82: 467-74. https://doi. org/10.1016/j.optm.2010.12.013.

8. Ma MM, Kang Y, Chen C et al. Vision therapy for intermittent exotropia: A case series. J Optom. 2020; 12: S1888-4296(20)30081-9. https://doi.org/10.1016/j.optom.2020.05.006.

9. Pejic Z, Wong A, Husain R et al. Fusion Exercises for Treatment of Intermittent Exotropia and Phoria. Am Orthopt J. 2006 ; 56: $138-46$. https://doi.org/10.3368/aoj.56.1.138.

10. Li X, Yang C, Zhang G et al. Intermittent Exotropia Treatment with Dichoptic Visual Training Using a Unique Virtual Reality Platform. Cyberpsychol Behav Soc Netw. 2019; 22(1): 22-30. https://doi.org/10.1089/cyber.2018.0259.

11. Vedamurthy I, Knill DC, Huang SJ et al. Recovering stereo vision by squashing virtual bugs in a virtual reality environment. Philos Trans R Soc Lond B Biol Sci. 2016; 371(1697): 20150264. https://doi.org/10.1098/rstb.2015.0264. 
12. Žiak P, Holm A, Halička J et al. Amblyopia treatment of adults with dichoptic training using the virtual reality oculus rift head mounted display: preliminary results. BMC Ophthalmol. 2017; 17(1): 105. https://doi.org/10.1186/s12886-017-0501-8.

13. Serrano-Pedraza I, Manjunath V, Osunkunle $O$ et al. Visual suppression in intermittent exotropia during binocular alignment. Invest Ophthalmol Vis Sci. 2011; 52(5): 2352-64. https://doi.org/10.1167/iovs.10-6144.

Authors' contributions:

Dorota Maciaszek: optometric examination, supervision of VT's treatment, writing - original manuscript;

Monika Wojtczak-Kwaśniewska: original manuscript.

Conflict of interest:

Dorota Maciaszek is a member of RemmedVR's research and development team, within the Intelligent Development Programme 2014-2020,

National Centre for Research and Development in Poland. Monika Wojtzak-Kwaśniewska has no conflict of interest.

Financial support:

None.

Ethics:

The content presented in the article complies with the principles of the Helsinki

Declaration, EU directives and harmonized requirements for biomedical journals. 